\title{
Molecular diversity of Azerbaijani wild and cultivated barley genotypes
}

\author{
Moozhan Serpoush \\ Center for Cell Pathology Research, Department of Life Sciences, Khazar University, Azerbaijan
}

\section{Article history:}

Received: 24 July, 2021

Revised: 18 Aug., 2021

Accepted: 03 Sept., 2021

\section{Citation:}

S Moozhan. 2021. Molecular diversity of Azerbaijani wild and cultivated barley genotypes. Journal of Cereal Research 13 (Spl-1): 37-42. http://doi.org/10.25174/25822675/2021/115268

\section{*Corresponding author:}

E-mail: moozhan.serpoush@khazar.org

(C) Society for Advancement of Wheat and Barley Research

\begin{abstract}
In this study the genetic diversity of Azerbaijan barley, nuclear genomes of 13 cultivated and 9 wild barley accessions were analyzed at population and individual levels using twenty ISSR primers. In total, 304 fragments were amplified, of which 263 were found to be polymorphic. High genetic diversity indices for ISSR markers (0.714) suggested that this method was equally effective in determining genetic variation in barley accessions. The highest and the lowest similarity indexes were equal to 0.92 and 0.20 , respectively. Cluster analysis based on Nei's genetic distance values showed that genotypes could be grouped into seven main clusters. Furthermore, no differences between the wild and cultivated barley accessions were revealed. Screening a higher number of anonymous loci in barley using ISSR markers will enable the selection of the best parent cultivars for the development of novel varieties.
\end{abstract}

Key words: Genetic diversity, molecular markers, ISSR, wild and cultivated barley

\section{Introduction}

To maintain genetic diversity, wild types and land races are the most important feature of the primary gene pool. Protecting and identifying a variety of crop plants for breeding programs and promoting breeders' interest is important for gene banks and genetic documentation (Ferdaous Guasmi, 2012).

Barley was one of the earliest crops to be domesticated. It is highly adaptable to a variety of environments due to its extensive phenotype and genetic diversity (Kumar et $a l ., 2014)$. As a result, its wild progenitor species can be found in western Asia, which provides a very rich genetic diversity resource. Barley has been domesticated and cultivated in highly diverse areas of the world (Stein and Muehlbauer 2018) (Newton et al., 2011). Among the cereal crop, Barley is considered to be particularly tolerant of drought and salinity. Due to its wide adaptability range, barley is a versatile crop. There are numerous cultivated collections of germplasm in the barley family (Hordeum vulgare ssp. vulgare) and wild barley (Hordeum vulgare ssp. spontaneum) (Bockelman and Valkoun, 2010) and in recent years it has been used in different breeding programs for instance, model for wheat breeding. About 141 million tons of barley is grown annually on around 48 million hectares around the world (FAO, 2018). Due to its nutritional value, barley is regarded as an essential food component and is utilized in the food, feed, and beverage sectors (Shaveta et al., 2019).

Genetic variation is the key tool for crop development and improved plant resistance to abiotic and biotic stresses. Barley is considered a good genetic model for Triticeae and more genetically complex cereal crops like hexaploid bread wheat (Kleinhofs and Han 2002). Barley (Hordeum vulgare) is the fourth major cereal in terms of production after maize, rice and wheat. Traditionally, morphological traits, cytological characters, biochemical tests, and pedigree information are used to assess genetic diversity and classify barley germplasm. However, these methods are always associated with various limitations 
and are insufficient to reveal the whole information within barley resources (Matus and Hayes, 2002). DNA molecular markers are the best tool to identify the polymorphisms and genetic diversity. PCR based marker such as random amplified polymorphic DNA (RAPD) and inter simple sequence repeat (ISSR) have been widely used to study genetic diversity. Genetic adaptability, difference between accessions and between transgenic and non-transgenic chrysanthemum plants are being identified by ISSR markers (Cid-Contreras et al., 2019). Extreme diversity of the soil and climatic conditions of Azerbaijan Republic support a very rich diversity of plant genetic resources. To preserve and use efficiently in the future the current genetic pool, it is necessary to evaluate the extent of this diversity by identification and distinction of Azerbaijan barley accessions, as well as the determination of genetic relationship between cultivated and wild relatives.

\section{Material and Methods}

\subsection{Plant material}

The experiment was performed using 9 wild and 13 cultivar barley samples. All the samples were obtained from the collection of the National Genbank of Azerbaijan which located in Genetic Resources Institute of the Azerbaijan National Academy of Sciences. (Table1).

Table 1. Names and genebank code of studied wild and cultivated barley accessions for assessing molecular diversity

\begin{tabular}{cccc}
\hline Code & Specimens & Code & Specimens \\
\hline 2262 & jalilabad-19 & 10128 & AZE AG-1880NH-16 \\
2273 & nutans-214/92 & 12375 & Aze Nur \\
2277 & Jabrayil-78 & 7012 & H. spontaneum 1 \\
2308 & Huseyin-1 & 7013 & H. spontaneum 2 \\
2329 & Nakhchivandani & 7014 & H. spontaneum 3 \\
2534 & Garabagh-7 & 7015 & H. spontaneum 4 \\
8255 & 8255 & 7016 & H. spontaneum 5 \\
8796 & AZE Ag-523az8LAb-1 & 7018 & H. spontaneum 6 \\
8802 & AZE Ag-529az8LAb-16 & 7019 & H. spontaneum 7 \\
8816 & AZE AG-543 & 7020 & H. spontaneum 8 \\
9801 & AZE N24 Jabrail & 7021 & H. spontaneum 9 \\
\hline
\end{tabular}

\subsection{DNA extraction}

Total DNA was extracted by the CTAB method of Doyle and Doyle (1990) in two repetitions to analyze genetic diversity directly at the level of the nuclear genome using ISSR primers. Nanodrop spectrophotometer was used to assess purity and quality of extracted DNA specimens. The ISSR primers used in the study are listed in Table 2. Isolated DNA specimens were amplified in a total reaction volume of $25 \mu \mathrm{L}$ comprising of $50 \mathrm{ng}$ DNA with the buffer (10 mM Tris-HCl, $\mathrm{pH} 8.0 ; 50 \mathrm{mM} \mathrm{KCl} ; 1.5 \mathrm{mM}$ $\left.\mathrm{MgCl}_{2}\right) ; 5 \mathrm{mM} \mathrm{MgCl}, 10 \mathrm{mM}$ of each dNTP; $10 \mathrm{mM}$ primer; and $0.1 \mu \mathrm{L}$ of $T a q$ polymerase. Polymerase chain reaction was performed in a Gene Amp 9700 thermal cycler (Applied Biosystems). The reaction conditions consisted of DNA denaturation at $94^{\circ} \mathrm{C}$ for $5 \mathrm{~min}$, followed by 35 cycles of $94^{\circ} \mathrm{C}$ for $1 \mathrm{~min}, 50^{\circ} \mathrm{C}$ for $2 \mathrm{~min}$, and $72^{\circ} \mathrm{C}$ for $5 \mathrm{~min}$, and final extension for $10 \mathrm{~min}$ at $72^{\circ} \mathrm{C}$. Amplification products were separated by electrophoresis in $2 \%$ agarose gel, stained with $0.05 \%$ ethidium bromide solution, and visualized in UV light using the Bio-Rad gel documentation system. The reproducible alleles amplified were scored as 1 for presence or 0 for absence. The software packages SYSTAT 13, PowerMarker, and PAST were used to examine amplified fragments and phylogenetic relationships. The following formula was used to calculate polymorphism information content as a genetic parameter: $\mathrm{PIC}=1-\left(\mathrm{P}_{\mathrm{ij}}\right) 2$, where $\mathrm{P}_{\mathrm{ij}}$ is the frequency of the $i$ th revealed pattern using the $j$ th primer. 
Table 2. The primer sequences and parameters of genetic variation generated by ISSR markers

\begin{tabular}{cccccccccccc}
\hline Primers & $\begin{array}{c}\text { Sequences } \\
\mathbf{5}^{\prime}-\mathbf{3}^{\prime}\end{array}$ & TAB & NPB & PPB & PIC & Primers & $\begin{array}{c}\text { Sequences } \\
\mathbf{5}^{\prime}-\mathbf{3}^{\prime}\end{array}$ & TAB & NPB & PPB & PIC \\
\hline UBC-810 & $(\mathrm{GA}) 8 \mathrm{~T}$ & 15 & 15 & 100 & 0.82 & ISSR6 & $(\mathrm{AC}) 8 \mathrm{C}$ & 9 & 9 & 100 & 0.33 \\
UBC-812 & $(\mathrm{GA}) 8 \mathrm{~A}$ & 20 & 17 & 85 & 0.34 & ISSR7 & $(\mathrm{GA}) 8 \mathrm{GG}$ & 21 & 21 & 100 & 0.59 \\
UBC-814 & $(\mathrm{CT}) 8 \mathrm{~A}$ & 14 & 13 & 92.86 & 0.38 & ISSR8 & $(\mathrm{CA}) 8 \mathrm{AG}$ & 12 & 7 & 58.33 & 0.95 \\
UBC-815 & $(\mathrm{CT}) 8 \mathrm{G}$ & 18 & 18 & 100 & 0.44 & ISSR18 & $(\mathrm{CA}) 8 \mathrm{AGC}$ & 23 & 15 & 65.22 & 0.85 \\
UBC-822 & $(\mathrm{TC}) 8 \mathrm{~A}$ & 10 & 9 & 90 & 0.93 & ISSR19 & $(\mathrm{AC}) 8 \mathrm{G}$ & 16 & 16 & 100 & 0.75 \\
UBC-834 & $(\mathrm{AG}) 8 \mathrm{YT}$ & 11 & 10 & 90.91 & 0.62 & ISSR20 & $(\mathrm{AC}) 8 \mathrm{CTG}$ & 14 & 10 & 71.43 & 0.97 \\
UBC-845 & $(\mathrm{CT}) 8 \mathrm{RG}$ & 17 & 11 & 64.70 & 0.29 & ISSR21 & $(\mathrm{AGT}) 6$ & 11 & 10 & 90.90 & 0.98 \\
ISSR1 & $(\mathrm{AC}) 8 \mathrm{G}$ & 16 & 14 & 87.50 & 0.88 & ISSR22 & $(\mathrm{GAA}) 6$ & 13 & 13 & 100 & 0.82 \\
ISSR2 & $(\mathrm{TC}) 8 \mathrm{C}$ & 10 & 10 & 100 & 0.79 & Total & - & 304 & 263 & - & - \\
ISSR3 & $(\mathrm{TG}) 8 \mathrm{G}$ & 17 & 15 & 88.23 & 0.96 & Minimum & - & 9 & 7 & 58.33 & 0.29 \\
ISSR4 & $(\mathrm{AC}) 8 \mathrm{GA}$ & 25 & 21 & 84 & 0.90 & Maximum & - & 25 & 21 & 100 & 0.98 \\
ISSR5 & $(\mathrm{GA}) 8 \mathrm{C}$ & 12 & 9 & 75 & 0.69 & Mean & - & 15.20 & 13.15 & 87.20 & 0.714 \\
\hline
\end{tabular}

*Y: C or T, R: A or T, TAB: Total amplified bands, NPB: Number of polymorphic bands, PPB: Percentage of polymorphic bands, PIC: Polymorphism information content.

\section{Results and Discussion}

\subsection{Marker's polymorphism}

Characterization of the genetic relationship among different wild and cultivated barley accessions was conducted with 20 ISSR primers. Twenty ISSR primers amplified a total of 304 bands in all studied wild and cultivated accessions, of which 263 bands were polymorphic. The number of bands varied from twenty-five (ISSR4) to nine (ISSR6). The percentage of polymorphic bands $(\mathrm{PPB})$ ranged between 58.33 and 100 with an average of $87.20 \%$ (Table 2). The mean number of bands and polymorphic bands per primer were 15.20 and 13.15, respectively. Drine et al. (2016) explained that the number of polymorphic bands $(72.2 \%)$ detected by ISSR markers was much higher than that of RAPD (61\%) marker. Similar results were reported by Tonk et al. (2014) who recommended ISSR in respect to higher polymorphism in triticale genotypes. However, Guasmi et al. (2012) revealed that RAPD markers were superior to ISSR markers in the capacity of revealing more informative bands in a single amplification in barley accessions.

The first cluster included four cultivated genotypes such as Huseyin-1, Garabagh-7, AZE Ag-529az8LAb-16, AZE AG-543 and one from wild type populations $H$. spontaneum 1. The second cluster was the largest and contained 7 genotypes, i.e. $31.82 \%$ of all genotypes; 5 of them were cultivated (Nakhchivandani, Aze Nur, nutans-214/92, AZE Ag-523az8LAb-1 and genotype $8255)$, but the $H$. spontaneum 9 and $H$. spontaneum were will type, respectively. However, cluster third and sixth consisted of only one genotype each, jalilabad-19 and $H$. spontaneum 8, respectively, which represents a genetic distance of these samples from other studied wild and cultivated barley accessions.

As it can be seen in the table, all the 20 used ISSR primers could identify all studied Azerbaijan wild and barley accessions. The highest primers polymorphic information content (PIC) among all the barley genotypes recorded for primers ISSR21 (0.98), ISSR20 (0.97), ISSR3 (0.96), ISSR8 (0.95), UBC-822 (0.93) and ISSR4 (0.90) and the lowest genetic diversity was observed with UBC845 primer (0.29). The mean genetic diversity index as estimated by PIC index was 0.714 , revealing a quite high level of genetic diversity in studied germplasm at molecular level. The suitability of the ISSR technique for genetic diversity studies and germplasm evaluations has been shown in many studies (Sofalian et al., 2008; Guliyev et al., 2018; Felix et al., 2020) 


\subsection{Genetic relationship and clustering analysis}

The similarity coefficients based on 20 ISSR alleles ranged from 0.20 to 0.92 . The highest similarity index (0.92) was observed between No 2 (nutans-214/92) with No. 8 (AZE Ag-523az8LAb-1), No. 2 (nutans-214/92) with No. 13 (Aze Nur), No. 2 (nutans-214/92) with No. 17 ( $H$. spontaneum 4$)$, while the lowest similarity $(0.20)$ was noted between 1 (jalilabad-19) with No. 21 (H. spontaneum 8) and No. 14 (H. spontaneum 1) with No. 21 (H. spontaneum 8). A high genetic similarity was also found between No. 8(AZE Ag-523az8LAb-1) with No. 22 (H. spontaneum 9) and No. 13 (Aze Nur) with No. 22 (H. spontaneum 9) (0.91), 10 with 14 (0.88).

In order to understand the phylogenetic relationship and genetic variation among barley accessions, the Jaccard similarity index and the dendrogram presented (Fig. 1). The genetic relationship among 22 barley accessions determined by UPGMA analysis and reveals seven major groups.

The first cluster included four cultivated genotypes such as Huseyin-1, Garabagh-7, AZE Ag-529az8LAb-16, AZE AG-543 and one from wild type populations $H$. spontaneum 1 . The second cluster was the largest and contained 7 genotypes, i.e. $31.82 \%$ of all genotypes; 5 of them were cultivated (Nakhchivandani, Aze Nur, nutans-214/92, AZE Ag-523az8LAb-1 and genotype $8255)$, but the $H$. spontaneum 9 and $H$. spontaneum were will type, respectively. The highest level of genetic similarity among the samples in this group related to AZE AG-543, Aze Nur and H. spontaneum 9 with a similarity index 0.91 .

However, cluster third and sixth consisted of only one genotype each, jalilabad-19 and $H$. spontaneum 8 , respectively, which represents a genetic distance of these samples from other studied wild and cultivated barley accessions. $H$. spontaneum- 6 and $H$. spontaneum- 7 both were grouped in fourth cluster which showed their closely DNA pattern.

Finally, cluster fifth and seventh contained three member each. In the cluster $\mathrm{V}$ one sample from cultivated barley (AZE AG-1880NH-16) and two samples from wild types (H. spontaneum-2 and $H$. spontaneum-3) were grouped. In this cluster the lowest genetic distance was observed between $H$. spontaneum 1 and $H$. spontaneum 8 with a similarity index 0.20 . Interestingly the varieties in the same group always share one or more common breeding ancestors according to pedigree information (Wang et al., 2010).

The results of this study should be useful both for identification of distinct accessions and establishment of core collections in gene banks, as well as utilization of genotypes in breeding programs. Nevertheless, further comprehensive assessment using different types and more polymorphic molecular markers could be necessary for elucidating genetic relationships among those 22 accessions grouped into the same highly heterogeneous cluster based on Jaccard's similarity indices.

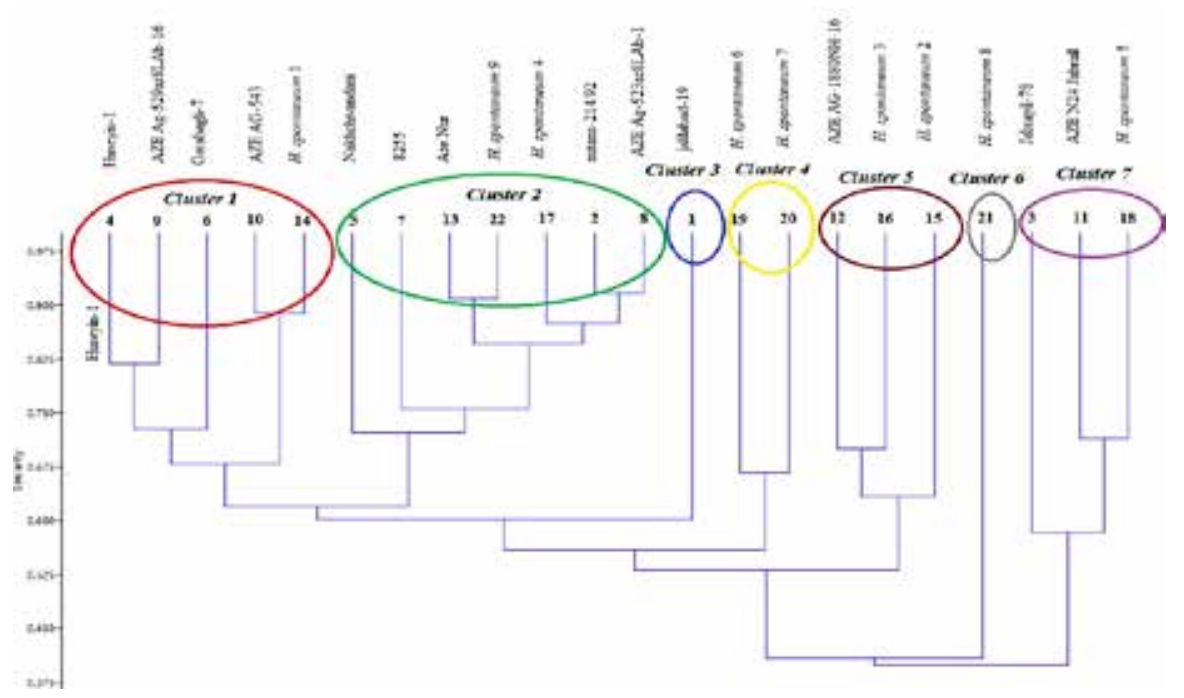

Fig. 1. Dendrogram of 22 barley accessions generated by the data from 20 ISSR primers. 


\section{Conclusions}

The present research was aimed at assessing the genetic structure among the twenty-two Azerbaijan barley accessions using ISSR markers. The ISSR technique seems to be convenient tool to investigate genetic diversity among studied wild and cultivated barley accessions. The elucidation of the relationships among the eight barley genotypes is an important resource for the breeding and management of barley germplasm. Our long-term objective is to determine the usefulness of molecular marker diversity as a tool for gene discovery. However, more genetic studies must be conducted, employing larger samplings of germplasm collections.

\section{Acknowledgement}

Dr.Javid Ojaghi, my supervisor, deserves my gratitude for his advice and support throughout all phases of my research.

\section{Ethical standards}

Not applicable with this article.

\section{Conflict of interest}

The authors declare that they have no conflict of interest.

\section{Author contributions}

MS: Collection of literature, Conceptualization, Compilation, Writing original draft, Final editing, Proof Reading

\section{References}

1. Bockelman HE and J Valkoun. 2010. Barley germplasm conservation and resources. In: Ullrich, S.E., editor, Barley: Improvement, production, and uses. Wiley-Blackwell, Oxford, UK. p. 144-159.

2. Cid-Contreras RC, JO Mascorro-Gallardo and E Valadez-Moctezuma. 2019. Genotyping and molecular analysis of transgenic sequences in chrysanthemum (Chrysanthemum $x$ morifolium Ramat). Crop Breeding and Applied Biotechnology 19(3): 285-290. http://dx.doi.org/10.1590/1984$70332019 v 19 n 3 a 40$

3. Drine S, F Guasmi, SB Ali, T Triki, F Boussorra and A Ferchichi. 2016. Genetic diversity analysis of different barley (Hordeum vulgare L.) genotypes from arid and humid regions using ISSR and
RAPD markers. Journal of New Sciences, Agriculture and Biotechnology 34(2): 1930-1939.

4. FAO. 2018. http://www.fao.org/faostat/en/\#data/ QC

5. Felix FC, Chagas, KPTD, Ferrari CDS, Vieira FDA and Pacheco MV. 2020. Applications of ISSR markers in studies of genetic diversity of Pityrocarpa moniliformis. Revista Caatinga 33(4):1017-1024.

6. Guasmi F, W Elfalleh, H Hannachi, K Fares, L Touil, N Marzougui, T Triki and A Ferchichi. 2012. The use of ISSR and RAPD markers for genetic diversity among south tunisian barley. Agronomy: 10 . doi:10.5402/2012/952196

7. Guliyev N, S Sharifova, J Ojaghi, M Abbasov, $\mathrm{Z}$ Akparov. 2018. Genetic diversity among melon (Cucumis melo L.) accessions revealed by morphological traits and ISSR markers. Turkish Journal of Agriculture and Forestry 42: 393-401.

8. Karaca G, G Tepedelen, A Belghouthi and AB Paul. 2008. A new mycoparasite, Pythium lycopersicum, isolated in Isparta, Turkey: morphology, molecular characteristics, and its antagonism with phytopathogenic fungi. FEMS Microbiology Letters 288(2):163-170.

9. Kleinhofs A and F Han. 2002. Molecular mapping of the barley genome. In: Slafer G, Molina-Cano JS, Savin R, Araus JL, Romagosa I, editors, Barley Science Recent Advances from Molecular Biology to Agronomy of Yield and Quality. Food Products Press, New York pp 665.

10. Kumar V, A Khippal, J Singh, R Selvakumar, R Malik, D Kumar, AS Kharub, RPS Verma and I Sharma. 2014. Barley research in India: Retrospect \& Prospects. Journal of Wheat Research 6(1):1-20

11. Matus IA and PM Hayes. 2002. Genetic diversity in three groups of barley germplasm assessed by simple sequence repeats. Genome 45(6):1095-1106. https://doi.org/10.1139/g02-071

12. Newton AC, AJ Flavell, TS George, P Leat, B Mullholland, L Ramsay, C Revoredo-Giha, J Russell, BJ Steffenson, JS Swanston. and WT Thomas. 2011. Crops that feed the world 4. Barley: a resilient crop? Strengths and weaknesses in the context of food security. Food Security 3: 141-178. 
13. Shaveta, H Kaur and S Kaur 2019. Hulless Barley: A new era of research for food purposes. Journal of Cereal Research 11(2): 114-124 doi.org/10.25174/22494065/2019/83719

14. Sofalian O, N Chaparzadeh, A Javanmard and M Hejazi. 2008. Study the genetic diversity of wheat landraces from northwest of Iran based on ISSR molecular markers. International Journal of Agriculture and Biology 10: 466-468.

15. Stein N and GJ Muehlbauer. 2018. The Barley Genome, Compendium of Plant Genomes. doi:10.1007/978-3-319-92528-8_8.
16. Tonk FA, M Tosun, E Ilker, D Istipliler, and O Tatar. 2014. Evaluation and comparison of ISSR and RAPD markers for assessment of genetic diversity in triticale genotype. Bulgarian Journal of Agricultural Science 20(6): 1413-1420.

17. Wang JM, JM Yang, JH Zhu, QJ Jia and YZ Tao. 2010. Assessment of genetic diversity by simple sequence repeat markers among forty elite varieties in the germplasm for malting barley breeding. Journal of Zhejiang University Science B 11(10):792-800. 